\title{
REDUÇÃO DA EROSÃO HÍDRICA EM TRÊS SISTEMAS DE MANEJO DO SOLO EM UM CAMBISSOLO HÚMICO DA REGIÃO DO PLANALTO SUL-CATARINENSE ${ }^{(1)}$
}

\author{
André Júlio do Amaral ${ }^{(2)}$, Ildegardis Bertol ${ }^{(3)}$, Neroli Pedro Cogo ${ }^{(4)} \&$ \\ Fabrício Tondello Barbosa ${ }^{(5)}$
}

\begin{abstract}
RESUMO
O preparo do solo situa-se entre os componentes de seu manejo mais importantes no processo de produção das plantas cultivadas, sendo normalmente usado para criar ambiente favorável à semeadura e germinação das sementes e ao crescimento das plantas. Em adição, ele é o principal responsável pela criação das condições físicas superficiais do solo que, em última análise, determinam a eficácia de redução da erosão e do escoamento superficial dos diversos sistemas de manejo empregados no estabelecimento de uma cultura, em um local. Considerando esses aspectos, realizou-se um estudo de erosão em campo, sob condições de chuva natural, no município de Lages (SC), na região fisiográfica do Planalto SulCatarinense, no período de novembro de 2002 a outubro de 2005 . O objetivo principal da pesquisa foi quantificar as perdas de água e solo nos ciclos culturais do trigo (Triticum aestivum L.) e da soja (Glycine max L.), usando os sistemas de manejo de solo convencional (aração+duas gradagens), reduzido (escarificação + uma gradagem) e sem preparo (semeadura direta), com vistas à determinação da eficácia de redução da erosão e do escoamento superficial dessas formas de manejo do solo. O experimento foi instalado em um Cambissolo Húmico alumínico léptico, apresentando textura superficial franco-argilo-siltosa e declividade média de $0,102 \mathrm{~m} \mathrm{~m}^{-1}$. Avaliaram-se características de planta e erosão hídrica em cinco
\end{abstract}

\footnotetext{
(1) Parte da Dissertação de Mestrado do primeiro autor. Recebido para publicação em outubro de 2006 e aprovado em agosto de 2008.

${ }^{(2)}$ Mestre em Solos, Faculdade de Agronomia, Universidade do Estado de Santa Catarina - CAV/UDESC. Caixa Postal 281, CEP 88520-000 Lages (SC). E-mail: ajulioamaral@yahoo.com.br

(3) Professor do Departamento de Solos, CAV/UDESC. Bolsista do CNPq. E-mail: a2ib@cav.udesc.br

(4) Professor Associado do Departamento de Solos, Universidade Federal do Rio Grande do Sul - UFRGS. Av. Bento Gonçalves 7712, Caixa Postal 15100, CEP 91501-970 Porto Alegre (RS). Bolsista do CNPq. E-mail: neroli@ufrgs.br

${ }^{(5)}$ Mestre em Solos, CAV/UDESC. E-mail: a6ftb@cav.udesc.br
} 
estádios de desenvolvimento das culturas, definidos com base na percentagem de cobertura do solo pelo dossel das plantas. A quantidade total de chuva foi praticamente a mesma (cerca de $650 \mathrm{~mm}$ ) em ambos os ciclos culturais, porém com alguma diferença na sua distribuição, tendo se concentrado mais no período que vai do intermediário ao final na cultura do trigo e no período inicial na cultura da soja. Este último comportamento se repetiu em relação à erosividade das chuvas, mas com os valores absolutos tendo sido diferentes em cada ciclo cultural (1.545 MJ mm ha-1 $\mathrm{h}^{-1}$ no ciclo do trigo e $2.573 \mathrm{MJ} \mathrm{mm} \mathrm{ha}^{-1} \mathrm{~h}^{-1}$ no ciclo da soja), refletindo-se nos resultados de perda de água e solo por erosão hídrica. $\mathrm{O}$ valor médio anual determinado do índice de erodibilidade do solo (fator $\mathrm{K}$ do modelo EUPS ou EUPSR de predição da erosão) foi de $0,018 \mathrm{MJ}^{-1} \mathrm{~mm}^{-1} \mathrm{ha}^{-1}$. As perdas médias anuais de água e solo em geral foram relativamente pequenas em todas as situações estudadas, embora com a da primeira variável sendo maior no ciclo cultural do trigo e a da segunda, maior no ciclo cultural da soja, bem como com ambos os tipos de perda decrescendo na ordem de preparo convencional, preparo reduzido e semeadura direta e com a perda de solo proporcionalmente sendo bem mais reduzida pelo manejo do que a perda de água. Os valores médios provisoriamente determinados do fator $\mathrm{C}$ - cobertura e manejo do solo, do modelo EUPS ou EUPSR, para a sucessão cultural trigo-soja, nas condições climáticas da região do estudo, foram iguais a 0,23 no sistema de manejo com preparo convencional do solo, 0,06 no sistema de manejo com preparo reduzido e 0,023 no sistema de manejo semeadura direta.

Termos de indexação: erosividade da chuva, erodibilidade do solo, preparo do solo, cultura do trigo, cultura da soja, fator $\mathrm{C}$ - cobertura e manejo do solo, EUPS, EUPSR.

\section{SUMMARY: REDUCTION OF WATER EROSION IN THREE SOIL MANAGEMENT SYSTEMS IN AN INCEPTISOL OF THE PLANALTO SUL-CATARINENSE REGION - BRAZIL}

\footnotetext{
Tillage is one of the most important components of soil management in the process of crop production, normally used to create a favorable environment for sowing, seed germination and plant development. In addition, it is mainly determinant for the or surface soil physical conditions that will ultimately determine the erosion and the effectiveness of runoff reduction of the various soil management systems used to establish a given crop, in a given place. Considering these aspects, a field study under natural rainfall erosion was conducted in Lages, in the Southern upland region of the State of Santa Catarina, Brazil, between November, 2002, and October, 2005. The main objective of the study was to quantify soil and water losses caused by water-rainfall erosion through wheat (Triticum aestivum, $L$.) and soybean (Glycine max, $L$ ) crop cycles, using conventional (one plowing and two diskings), reduced (one chiseling and one disking), and no tillage (direct seeding), to determine the erosion and effectiveness of runoff reduction of these forms of soil use and management. The experiment was planted on a silt clay loam Inceptisol, with $0.102 \mathrm{~m} \mathrm{~m}^{-1}$ mean slope steepness. Plant and water-rainfall erosion parameters were evaluated in five crop stages, defined on the basis of percent of soil cover per plant canopy. The total rainfall amount was about the same (approximately $650 \mathrm{~mm}$ ) in both crop cycles, with some variation in distribution, but with a greater concentration in the period from the middle to the end of the wheat cycle and the initial period of soybean. The rain erosivity pattern was similar, but with clearly different absolute values in each crop cycle $\left(1,545 \mathrm{MJ} \mathrm{mm} \mathrm{ha}^{-1} \mathrm{~h}^{-1}\right.$ in wheat and 2,573 $\mathrm{MJ} \mathrm{mm} \mathrm{ha-1} \mathrm{h}^{-1}$ in soybean). The determined mean annual value of the soil erodibility index (factor $K$ in the USLE or RUSLE erosion prediction model) was equal to $0.018 \mathrm{Mg}$ ha h ha-1 $\mathrm{MJ}^{-1} \mathrm{~mm}^{-1}$. The mean annual losses of soil and water were generally relatively small in all situations studied, although soil losses were greater in wheat and water losses higher in soybean. Both loss types decreased in the order conventional-, reduced-, and no-tillage. The soil loss was proportionally much more reduced by tillage than by water loss. The provisionally determined mean annual values of the $C$ factor-soil
} 
cover and management in USLE or in RUSLE erosion prediction model for the wheatsoybean crop sequence in the experimental climatic conditions were 0.23 when using conventional tillage, 0.06 for reduced tillage, and 0.023 for no-tillage or direct seeding.

Index terms: rain erosivity, soil erodibility, soil tillage, wheat crop, soybean crop, factor $C$ - soil cover and management, USLE, RUSLE.

\section{INTRODUÇÃO}

O preparo do solo destaca-se como uma das operações agrícolas mais importantes no processo de produção vegetal. Segundo Raney \& Zingg (1957), ele é efetuado com o propósito de modificar a estrutura do solo, para favorecer a semeadura e germinação das sementes e o crescimento das plantas, entre outras finalidades. As alterações mais visíveis na superfície do solo, decorrentes do seu preparo, estão relacionadas com a rugosidade e com a cobertura por resíduo cultural (Allmaras et al., 1966; Burwell et al., 1966), as quais variam com o sistema de manejo do solo adotado. Por essa razão, diz-se que o manejo do solo é o fator que mais influencia a erosão hídrica pluvial do solo.

Na classificação dos sistemas de manejo do solo, o não-conservacionista é todo aquele no qual são usados o arado e a grade para preparar a terra para o cultivo, ficando a superfície do solo fragmentada e diretamente exposta à ação das chuvas. Isso facilita a desagregação do solo pelo impacto das gotas da chuva e o seu transporte pela enxurrada (Hudson, 1995; Lindstrom et al., 1998). Em adição, o uso do arado e da grade induz a incorporação de quase todos os resíduos culturais ao solo, praticamente eliminando sua cobertura por esses materiais e deixando sua superfície vulnerável ao selamento superficial, o que reduz a taxa de infiltração de água no solo (Duley, 1939). Como conseüência desses fatos, a rugosidade superficial, que normalmente é alta logo após a operação de preparo do solo, é rapidamente diminuída neste sistema, favorecendo a ocorrência de grandes perdas por erosão (Burwell \& Larson, 1969; Cogo, 1981; Lindstrom et al., 1998; Castro et al., 2006). De outro lado, os sistemas conservacionistas de manejo do solo, como aquele em que é usado o escarificador, seguido ou não de grade, em geral se caracterizam por mobilizar pouco o solo, resultando em média a alta rugosidade superficial e em relativamente alta quantidade de resíduos culturais na superfície do solo (Cogo, 1981; Cogo et al., 1983; Bertol et al., 2006). No extremo dos sistemas de manejo de caráter conservacionista encontra-se aquele em que é utilizada a técnica de semeadura direta para implantar culturas, cuja operação de semeadura é efetuada, sem o preparo prévio do solo, resultando na menor mobilização entre todos os sistemas existentes e, conseqüentemente, na maior quantidade de resíduos culturais deixada na superfície do solo. Essa forma de implantar culturas normalmente é a que apresenta o mais baixo e o mais alto grau de rugosidade superficial e consolidação da superfície do solo, respectivamente (Cogo, 1981; Cogo et al., 1983; Bertol, 1995).

Os fatos anteriormente, aludidos à semeadura direta, fazem desta técnica a mais eficaz para se reduzir a perda de solo por erosão hídrica pluvial (Carvalho et al., 1990; Cogo et al., 2003), devido à sua alta resistência ao referido fenômeno (Dissmeyer \& Foster, 1981; Schick et al., 2000), embora apresentando baixa ou praticamente nula rugosidade superficial do solo. Entretanto, de modo geral, a semeadura direta não apresenta a mesma eficácia de redução da perda de água que a redução da perda de solo em se tratando da erosão hídrica pluvial, embora nesta, o solo normalmente apresenta maior continuidade de poros (Lindstrom et al., 1998), menor taxa de decomposição da matéria orgânica (Beare et al., 1994) e maior estabilidade de agregados, comparado ao solo nos sistemas que usam os equipamentos tradicionais de preparo (Bertol et al., 2004).

Embora, conforme foi exposto, o efeito do manejo do solo na redução da perda de água seja, em geral, menor do que na redução da perda de solo, alguns estudos têm evidenciado que determinados sistemas, que deixam os resíduos culturais na superfície do solo, também são eficazes na redução da perda de água, ao contrário de outros. Isso ocorre, em geral, quando a semeadura das culturas é feita sem o preparo prévio do solo, como acontece com a técnica de semeadura direta (Johnson \& Moldenhauer, 1979; Ghidey \& Alberts, 1998; Schick et al., 2000). A menor influência dos sistemas de manejo do solo na redução da perda de água, comparada com a redução da perda de solo, é explicada pelo fato de que todos os solos possuem um limite de capacidade de absorção e armazenamento de água. Ultrapassado esse limite, o excesso de água da chuva escoa sobre o terreno, praticamente igualando o efeito dos diferentes sistemas de manejo no que tange à sua eficácia de controle da perda de água por erosão (Kohnke, 1968).

A distribuição temporal das chuvas também altera as perdas de água e solo por erosão hídrica, uma vez que sua erosividade pode variar no tempo, em função de variações na intensidade, na duração e na freqüência de ocorrência destas. Assim, durante o ciclo de uma cultura, a erosividade das chuvas pode se concentrar no período de seu crescimento, que 
coincide com o período crítico de erosão, caracterizado por pouca ou nenhuma cobertura vegetal na superfície do solo, conforme enfatizado por Wischmeier \& Smith (1978). As plantas em crescimento influenciam a erosão hídrica pluvial porque o seu dossel cobre a superfície do solo e suas raízes melhoram as propriedades físicas deste último, facilitando o movimento de água no seu interior e, dessa forma, mantendo altas as taxas de infiltração de água no solo. A capacidade do dossel das plantas de interceptar gotas de chuva varia com a arquitetura e a morfologia destas, as quais, por sua vez, são peculiares a cada tipo de planta (Armstrong \& Mitchell, 1988; Gonzalez Hidalgo et al., 1996), bem como varia com o estádio de desenvolvimento das culturas (Wischmeier \& Smith, 1978). A cobertura do solo por resíduo cultural é mais eficaz na redução da perda de solo por erosão do que a equivalente cobertura pelo dossel das plantas (Wischmeier \& Smith, 1978). Os resíduos culturais dissipam a energia cinética das gotas da chuva no ponto de impacto sobre eles, junto à superfície do solo, evitando ou minimizando ao máximo a desagregação inicial do solo, ao mesmo tempo em que servem de barreira física à ação cisalhante e de transporte da enxurrada, resultando em menores perdas de água e solo por erosão hídrica pluvial.

Considerando os aspectos discorridos, o objetivo deste trabalho foi quantificar as perdas de água e solo por erosão hídrica pluvial em diferentes estádios de crescimento das culturas de trigo e soja, cultivadas em sucessão contínua, nos sistemas de manejo do solo convencional, reduzido e semeadura direta, com vistas à determinação da eficácia relativa de controle da erosão dessas formas de manejo do solo. De posse dessas informações, pretende-se sugerir valores do fator C-cobertura e manejo do solo do modelo EUPS (Equação Universal de Perda de Solo) ou EUPSR (Equação Universal de Perda de Solo Revisada), para as situações estudadas.

\section{MATERIAL E MÉTODOS}

O experimento foi instalado em um Cambissolo Húmico alumínico léptico (Embrapa, 1999), de textura superficial franco-argilo-siltosa e declividade média de 0,102 $\mathrm{m} \mathrm{m}^{-1}$, localizado no município de Lages (SC), na região do Planalto Sul-Catarinense, entre as coordenadas de $27^{\circ} 49^{\prime}$ de latitude sul e $50^{\circ} 20^{\prime}$ de longitude oeste (Greenwich), na altitude média de $937 \mathrm{~m}$. Esse solo é derivado da alteração de siltitos e argilitos da formação Rio do Rasto, estando situado próximo ao topo de uma pendente com, aproximadamente, $500 \mathrm{~m}$ de comprimento.

Estudaram-se, entre novembro de 2002 e outubro de 2005, os seguintes tratamentos de manejo do solo: cultivo de soja (Glycine max L.) no período de primavera-verão e de trigo (Triticum aestivum L.) no de outono-inverno, em sucessão contínua, nos preparos de solo convencional (PC - uma aração + duas gradagens), reduzido (PR - uma escarificação + uma gradagem) e semeadura direta (SD), os quais foram comparados a um tratamento testemunha ( $\mathrm{T}$ parcela-padrão ou unitária, segundo Wischmeier \& Smith, 1978), caracterizado pela ausência de cultivo e de vegetação espontânea e sendo preparado duas vezes ao ano no método convencional (uma aração + duas gradagens). Devido à falta de espaço físico adequado na área experimental e a dificuldades de implantação e condução de experimentos dessa natureza, bem como levando em conta o custo e o tempo envolvidos na sua implantação, os tratamentos referidos não sofreram repetição (optou-se, no seu lugar, por um maior número deles, para aumentar a quantidade de informações no assunto).

As operações de preparo do solo e semeadura das culturas foram efetuadas no sentido da pendente do terreno, conforme filosofia de obtenção do fator C cobertura e manejo do modelo USLE ou RUSLE de predição da erosão (Wischmeier \& Smith, 1978; Renard et al., 1997). A aração foi efetuada com arado de três discos, regulado para operar na profundidade de $0,20 \mathrm{~m}$ do solo. A escarificação foi realizada com equipamento escarificador, com sete hastes dianteiras e seis traseiras, distanciadas uma da outra de $0,25 \mathrm{~m}$, regulado para operar na profundidade de $0,15 \mathrm{~m}$ do solo. A gradagem foi efetuada com grade do tipo "tandem", com 32 discos, regulada para operar à profundidade de $0,12 \mathrm{~m}$.

Durante o período experimental, as culturas receberam fertilizantes químicos, equivalentes a $125 \mathrm{~kg} \mathrm{ha}^{-1}$ de $\mathrm{N}, 222 \mathrm{~kg} \mathrm{ha}^{-1}$ de $\mathrm{P}_{2} \mathrm{O}_{5}$ e $305 \mathrm{~kg} \mathrm{ha}^{-1}$ de $\mathrm{K}_{2} \mathrm{O}$, os quais foram incorporados ao solo no preparo convencional, semi-incorporados no preparo reduzido e distribuídos superficialmente na semeadura direta. No ciclo cultural compreendido entre novembro de 2002 e maio de 2003, a soja foi semeada com máquina manual tipo "matraca" ou "saraquá", e no ciclo cultural, entre maio e novembro de 2003, o trigo foi semeado manualmente, a lanço. Nos demais ciclos, a semeadura foi realizada de forma tratorizada, usando máquina semeadora-adubadora tipo de fluxo contínuo.

A unidade experimental foi constituída da tradicional parcela de escoamento, com dimensões de $3,5 \times 22,1 \mathrm{~m}\left(77,4 \mathrm{~m}^{2}\right)$, com a maior dimensão sendo disposta no sentido do declive. Cada parcela foi delimitada nas laterais e extremidade superior por chapas galvanizadas $(2 \times 0,2 \mathrm{~m})$, as quais foram cravadas $0,10 \mathrm{~m}$ no solo. Na extremidade inferior de cada parcela foi instalada uma calha especial para recolhimento da enxurrada, à qual se acoplou um cano plástico do tipo PVC, de $6 \mathrm{~m}$ de comprimento e $75 \mathrm{~mm}$ de diâmetro, o qual conduzia a enxurrada até o primeiro tanque de coleta (de sedimentação), com capacidade de armazenagem de $750 \mathrm{~L}$, localizado $6 \mathrm{~m}$ abaixo. Este tanque era ligado, por meio de um divisor de fluxo de água do tipo "Geib", com nove ranhuras, 
ao segundo tanque de coleta (de suspensão), também com capacidade de armazenagem de 750 L. Dessa forma, o divisor de água permitia a passagem de um nono da enxurrada do primeiro para o segundo tanque. A coleta, o processamento e a análise das amostras de enxurrada, para posterior cálculo das perdas de água e solo por erosão, foram efetuados seguindo o método descrito por Cogo (1978).

A cobertura do solo pelo dossel das plantas foi primeiramente avaliada aos cinco dias de emergência destas e, a partir desse momento, a cada 15 dias, usando o método do "metro sombreado", conforme descrito em Adams \& Arkin (1977), em três locais em cada parcela. Com base nessas medições, foram estabelecidos cinco estádios de crescimento ou desenvolvimento vegetativo das culturas, seguindo, aproximadamente, os mesmos critérios adotados por Wischmeier \& Smith (1978), assim especificados: estádio 1 - do preparo primário (da semeadura da cultura, no caso da semeadura direta) até $10 \%$ de cobertura do solo pelo dossel das plantas; estádio 2 de $10 \%$ de cobertura do solo pelo dossel das plantas até $30 \%$ de cobertura; estádio 3 - de $30 \%$ de cobertura do solo pelo dossel das plantas até $50 \%$ de cobertura; estádio 4 - de $50 \%$ de cobertura do solo pelo dossel das plantas até $75 \%$ de cobertura; e estádio 5 - de $75 \%$ de cobertura do solo pelo dossel das plantas até a colheita da cultura. A cobertura do solo pelos restos vegetais do cultivo anterior, em cada estádio referido, foi medida logo após a operação de preparo do solo e, ou, de semeadura da cultura e, a partir de então, a cada 15 dias, tendo sido efetuadas duas determinações por parcela, usando o método da corda marcada ou linha de transecção de pontos, conforme descrito em Hartwig \& Laflen (1978). Tendo em vista que a extensão (número de dias) de cada um dos estádios referidos variou pouco entre os métodos de preparo do solo investigados, fez-se uso dos seus valores médios para representá-los nas figuras deste trabalho.

Em algumas ocasiões ao longo do período experimental, houve coletas acumuladas de enxurrada, ou seja, amostras desta constituídas de mais de uma chuva (evento isolado de precipitação pluvial). Esse fato não é raro acontecer em experimentos dessa natureza. Diante disso, adotouse o procedimento descrito a seguir para calcular a erosividade das chuvas que tomaram parte na experimentação, usando pluviogramas com capacidade de registro de precipitação de $10 \mathrm{~mm}$ e escala de leitura de $0,01 \mathrm{~mm}$, com tempo de registro de $24 \mathrm{~h}$ e escala de leitura de $10 \mathrm{~min}$, acionados por pluviógrafo instalado a, aproximadamente, $600 \mathrm{~m}$ da área experimental. Após manualmente cotarem-se as alturas de chuva nos pluviogramas em segmentos de intensidade uniforme (mesmo declive da curva), usouse o programa desenvolvido por Cataneo et al. (1982) para calcular a energia cinética e a erosividade das chuvas (fator R da EUPS ou EUPSR), adotando-se o índice $\mathrm{EI}_{30}$ de Wischmeier \& Smith (1978). No referido programa, é utilizada a seguinte equação no cálculo da energia cinética, por $\mathrm{mm}$ de chuva, das chuvas naturais, a qual também foi desenvolvida por Wischmeier \& Smith (1978) e convertida para o Sistema Internacional de Unidades por Foster et al. (1981):

$$
\mathrm{Ec}=0,119+0,0873 \log _{10} \mathrm{I}
$$

em que $\mathrm{Ec}=$ energia cinética por $\mathrm{mm}$ de chuva, $\mathrm{MJ} \mathrm{ha}^{-1} \mathrm{~mm}^{-1}$; e I = intensidade da chuva, $\mathrm{mm} \mathrm{h}^{-1}$.

A soma dos valores de Ec permitiu obter a energia cinética total da chuva (Et), enquanto o produto de Et pela intensidade máxima da chuva num período consecutivo de 30 minutos $\left(\mathrm{I}_{30}\right)$ possibilitou a obtenção do seu índice de erosividade $\left(\mathrm{EI}_{30}\right)$. Tendo em vista a ocorrência de coletas acumuladas de enxurrada (amostras constituídas de mais de uma chuva), os critérios usados para separar e analisar chuva individual e chuva erosiva, neste trabalho, foram os propostos por Wischmeier \& Smith (1958). Com base nesses critérios, as chuvas individuais erosivas totalizaram 123 em número e $3.484 \mathrm{~mm}$ em altura de lâmina de água.

A eficácia de redução das perdas de água da chuva e de solo por erosão, de cada um dos sistemas de manejo do solo investigados, em cada uma das culturas inseridas no experimento, foi determinada pela razão entre a perda de água e a perda de solo de cada um deles e a perda de água e a perda de solo da parcela unitária ou padrão (tratamento testemunha ou sem cultivo), observadas no final do ciclo das culturas, expressando-se os resul-tados como média dos três anos de experimentação.

\section{RESULTADOS E DISCUSSÃO}

\section{Cobertura do solo}

Os valores de cobertura do solo pelo resíduo cultural de cada uma das culturas referidas foram semelhantes entre si, razão pela qual é utilizada a sua média (Figura 1). Assim, analisando os dados, verifica-se que a cobertura do solo pelo resíduo cultural mantevese praticamente inalterada no tempo em qualquer método de preparo, porém com diferenças marcantes entre eles. Quanto à cobertura pelo dossel das plantas, ela aumentou progressivamente com o desenvolvimento destas, com pequena diferença entre os tipos de cultura.

A cobertura do solo pelo resíduo cultural praticamente não variou no tempo em razão do período relativamente curto dos ciclos culturais do trigo e da soja, associado às características climáticas da região do estudo (altitude elevada e temperaturas baixas), o que fez com que a decomposição dos restos vegetais fosse pequena. Por sua vez, a diferença nos valores 


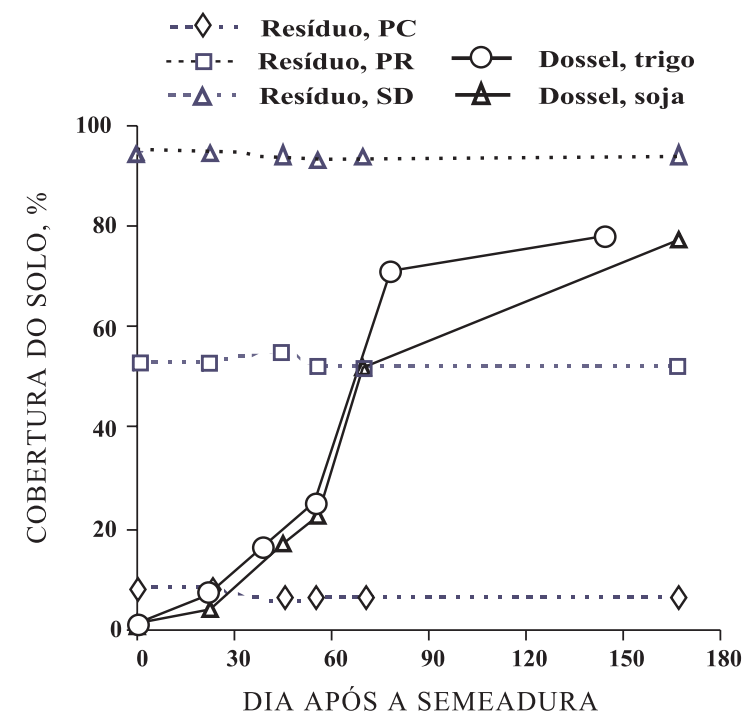

Figura 1. Cobertura do solo pelo resíduo cultural e pelo dossel das plantas, ao longo do desenvolvimento das culturas, nos tratamentos estudados (PC: preparo convencional; PR: preparo reduzido; SD: semeadura direta; obs.: em todos os casos, valores médios de três anos de experimentação).

de cobertura do solo pelo resíduo cultural entre tratamentos é explicada pelos diferentes tipos de equipamento e operação de preparo propriamente dita, utilizados em cada um deles. Isso influenciou a quantidade e a profundidade de mobilização do solo e, por conseguinte, a quantidade de resíduo cultural incorporada em sua massa. Assim, devido à ação do arado e da grade, o preparo convencional (PC) incorporou ao solo a maior quantidade de resíduo cultural, resultando no menor valor de cobertura superficial, ao passo que o preparo reduzido $(\mathrm{PR})$ e a semeadura direta (SD), em razão do uso do escarificador mais grade e da ausência de preparo, ficaram com os valores intermediário e maior, respectivamente. Esses resultados são condizentes com os encontrados por Cogo (1981) e Schick et al. (2000), em estudos de mesma natureza.

No que se refere à cobertura do solo pelo dossel das plantas (Figura 1), o seu aumento no tempo deveu-se ao crescimento progressivo destas, o que é normal e dispensa comentários. Contudo, a pequena diferença nos valores de cobertura do solo pelo dossel das plantas de trigo e soja é explicada pelas diferenças na sua constituição morfológica e arquitetônica, o que também é normal e dispensa comentários. Resultados semelhantes a esses também foram obtidos por outros autores (Wischmeier \& Smith, 1978; Armstrong \& Mitchell, 1988; Gonzalez Hidalgo et al., 1996; De Maria \& Lombardi Neto, 1997).

\section{Quantidade e erosividade das chuvas}

Analisando os dados de quantidade e erosividade das chuvas que tomaram parte no experimento, verifica-se que a primeira variável mostrou comportamento semelhante no que se refere tanto à magnitude quanto à distribuição temporal de seus valores, tanto durante o ciclo cultural do trigo quanto durante o ciclo cultural da soja; já a segunda variável apresentou comportamento diferente, com valores menores e variação mais acentuada no período correspondente ao ciclo cultural do trigo (Figura 2).

Os maiores valores de erosividade das chuvas observados no ciclo cultural da soja devem-se às maiores intensidades destas, ocorrentes no período de primavera-verão, contrastadas com as intensidades que normalmente ocorrem no período de outonoinverno, correspondente ao ciclo cultural do trigo, o que está em conformidade com as condições de clima tropical e subtropical - este último tipo sendo o característico da região de estudo. Quanto à variação temporal dos valores da variável em pauta, observase que, no ciclo cultural do trigo, eles se concentraram mais a partir dos 60 dias de semeadura da cultura, enquanto no ciclo cultural da soja eles variaram menos, porém com alguma concentração nos seus estádios iniciais. Esses resultados estão em conformidade com os encontrados por Bertol et al. (2002), para a mesma região fisiográfica deste estudo. Como será visto adiante, as diferenças na magnitude dos valores e na distribuição do índice de erosividade das chuvas, observadas entre os ciclos culturais do trigo e da soja, se refletiram nos resultados de perdas de solo e água por erosão.
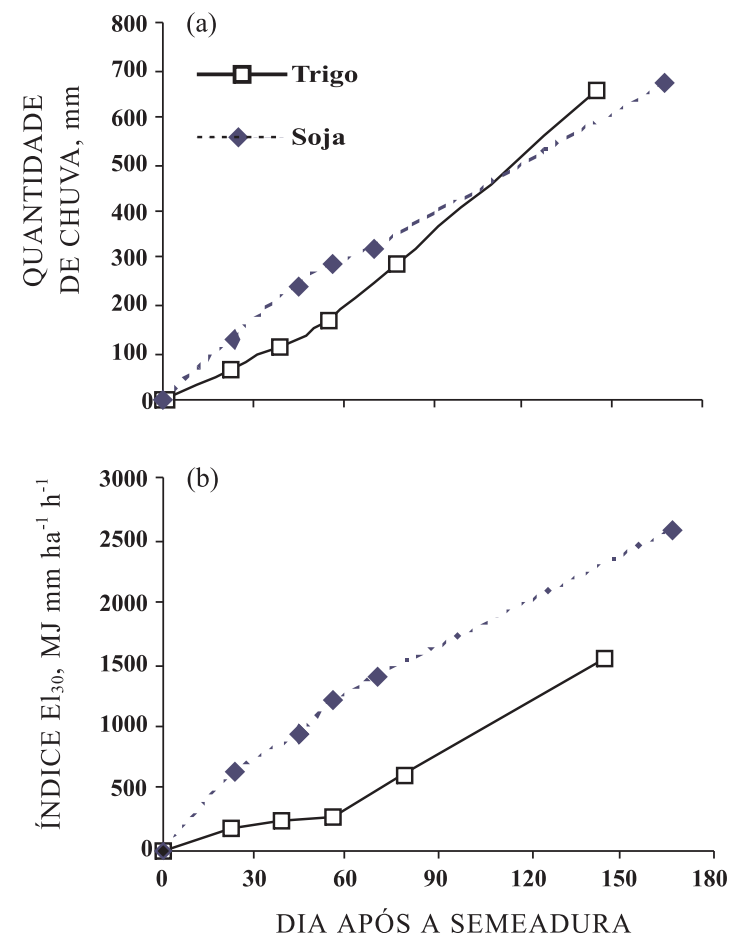

Figura 2. Quantidade (a) e índice $\mathrm{EI}_{30}$ de erosividade das chuvas (b), ao longo do desenvolvimento das culturas (valores médios de três anos de experimentação). 


\section{Perda de água}

Analisando os resultados de perda de água da chuva na forma de enxurrada (Figura 3), verifica-se que eles variaram consideravelmente com as situações estudadas. Assim, observa-se que, tanto no tratamento testemunha (T - Figura 3a) quanto nos tratamentos principais de manejo do solo (PC, PR e SD - Figura 3b), a perda de água da chuva na forma de enxurrada, em geral, foi maior durante o ciclo cultural do trigo do que durante o ciclo cultural da soja. No que se refere à primeira cultura, ela foi mais expressiva a partir do seu estádio intermediário (aproximadamente dos 6075 dias após a semeadura), enquanto para a segunda cultura ocorreu o contrário, ou seja, ela foi mais expressiva nos seus estádios iniciais (aproximadamente até os 30-45 dias da semeadura). Isso ocorreu independentemente do método de preparo do solo utilizado, mas com diferenças marcantes entre eles. A maior perda de água observada durante o ciclo cultural do trigo, comparada à observada durante o ciclo cultural da soja, provavelmente se deveu à maior umidade no solo no período de outono-inverno, em relação à normalmente verificada no período de primavera-verão, bem como às diferenças na morfologia e na arquitetura das plantas. Isso ocorreu mesmo com a quantidade total de precipitação pluvial e sua distribuição temporal tendo sido semelhantes nos dois ciclos culturais (Figura 2a) e com a erosividade total das chuvas tendo sido maior durante o ciclo cultural da soja (Figura 2b). Quanto à maior perda de água nos estádios iniciais da cultura da soja e a partir do estádio intermediário da cultura do trigo, ela se deveu às maiores quantidade e erosividade das chuvas nesses períodos (Figura 2).

No tocante à perda de água nos tratamentos principais de manejo do solo (Figura 3b), de modo geral ela foi maior no preparo convencional (PC) e menor na semeadura direta (SD), ficando o preparo reduzido (PR) em posição intermediária, em ambos os ciclos das culturas. Esses resultados são explicados pelas diferenças nas condições físicas superficiais do solo, resultantes dos diferentes manejos. Assim, o preparo convencional, devido à ação do arado e da grade, mobilizou muito o solo, incorporando em sua massa a maior parte dos resíduos culturais preexistentes e deixando a sua superfície praticamente descoberta ( $8 \%$, na média dos ciclos culturais e dos anos de experimentação - Figura 1). Além disso, nesta forma de preparo, o solo ficou bastante fragmentado, com torrões de médio a pequeno porte, portanto, com média a baixa rugosidade superficial do solo. Isso favoreceu o selamento superficial e diminuiu a capacidade de retenção superficial de água do solo, reduzindo a infiltração de água neste e aumentando o escoamento superficial. Já no preparo reduzido, a superfície do solo se encontrava relativamente bem protegida pelo resíduo cultural preexistente ( $55 \%$, na média dos ciclos culturais e dos anos de experimentação Figura 1), menos mobilizada e com média a alta rugosidade superficial, o que aumentou a capacidade de retenção superficial de água do solo e, conseqüentemente, a sua infiltração neste, diminuindo a perda de água na forma de enxurrada. Quanto à semeadura direta, sua menor perda de água pode ser explicada pela manutenção praticamente integral dos resíduos culturais na superfície do solo, evitando o selamento superficial e, por conseguinte, auxiliando a infiltração de água e reduzindo o escoamento superficial, embora apresentando ela a menor rugosidade superficial entre os três sistemas de manejos investigados. O fato de, na semeadura direta, o solo não ter sido mobilizado por ocasião da implantação das culturas, provavelmente, manteve a continuidade de poros melhor e, com isso, auxiliou a infiltração de água, melhorando assim o movimento interno de água no seu perfil.

Independentemente do que foi comentado, deve-se ressaltar o fato de que, no final do ciclo das duas culturas, a perda de água da chuva na forma de enxurrada foi baixa (Figura 3), comparada ao total precipitado em cada ciclo cultural $(650 \mathrm{~mm})$. Isso denota tanto a relativamente boa capacidade de infiltração de água do solo utilizado no estudo, quanto a relativamente uniforme distribuição das chuvas na região fisiográfica onde ele foi realizado.

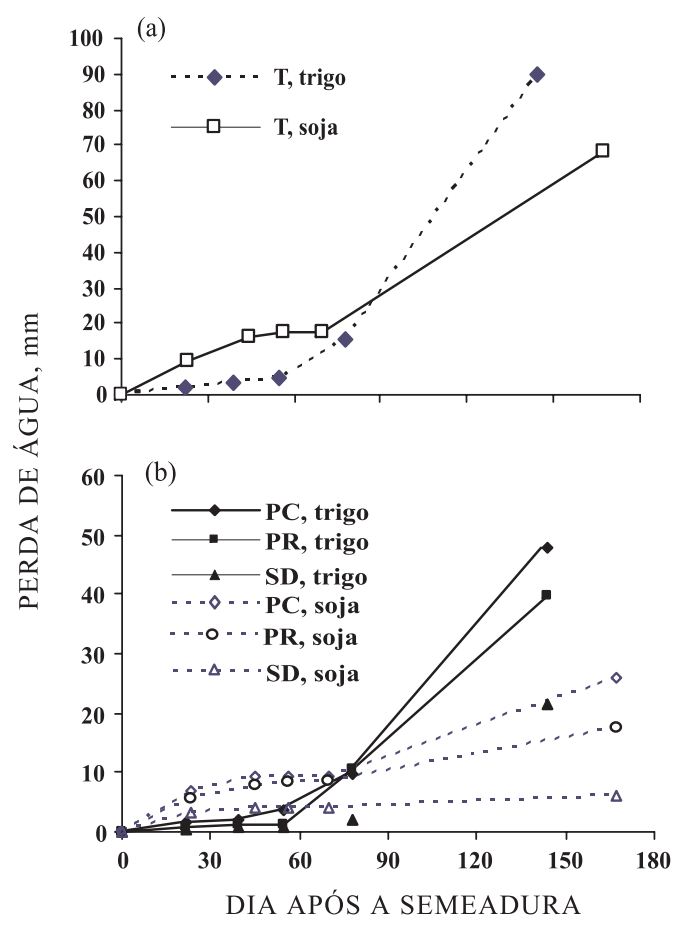

Figura 3. Perda de água da chuva na forma de enxurrada no tratamento sem cultivo (a) e nos tratamentos com cultivo (b), ao longo do desenvolvimento das culturas (T: testemunha; PC: preparo convencional; PR: preparo reduzido; SD: semeadura direta; obs.: em todos os casos, valores médios de três anos de experimentação). 


\section{Perda de solo}

Analisando os dados relativos a esta variável (Figura 4), verificam-se diferenças entre tratamentos no que se refere tanto à magnitude dos seus valores quanto ao seu comportamento, dentro e entre os ciclos culturais. Assim, no tratamento testemunha (T Figura 4a), a perda de solo foi expressivamente maior no ciclo cultural da soja do que no ciclo cultural do trigo, com maior expressão nos estádios iniciais da primeira cultura (até os 30-45 dias da semeadura) e nos estádios seguintes ao intermediário da segunda cultura (a partir dos 45-60 dias da semeadura). Nos tratamentos principais (PC), (PR) e (SD) (Figura 4b) ocorreu o inverso, ou seja, a perda de solo em geral foi um pouco maior no ciclo cultural do trigo do que no ciclo cultural da soja, exceto o preparo convencional nesta última cultura, o qual apresentou o maior valor da variável em pauta o tempo todo.

A maior perda de solo no tratamento testemunha (sem cultivo), correspondente ao ciclo cultural da soja, comparada à verificada no período correspondente ao ciclo cultural do trigo, deveu-se à maior erosividade das chuvas em tal período (Figura 2). Por sua vez, a maior perda de solo neste tratamento no período de tempo correspondente aos estádios iniciais da cultura da soja e no período de tempo correspondente aos estádios seguintes ao intermediário da cultura do trigo foi devida à concentração da erosividade das chuvas nestes (Figura 2b). Com os valores de perda de solo do tratamento testemunha ( $\mathrm{T}$ - Figura 4a) e de erosividade das chuvas (Figura 2b), obtidos no final do período de tempo correspondente ao ciclo cultural de cada cultura, foi possível provisoriamente calcular o índice de erodibilidade do solo ou fator $\mathrm{K}$ do modelo USLE ou RUSLE de predição da erosão para o solo do estudo. Os resultados encontrados foram, respectivamente, de $0,012 \mathrm{Mg}$ ha $\mathrm{h} \mathrm{MJ}^{-1} \mathrm{~mm}^{-1} \mathrm{ha}^{-1}$ durante o ciclo cultural do trigo e de $0,024 \mathrm{Mg}$ ha $\mathrm{h}$ $\mathrm{MJ}^{-1} \mathrm{~mm}^{-1} \mathrm{ha}^{-1}$ durante o ciclo cultural da soja, perfazendo o valor médio para o conjunto dos ciclos de 0,018 $\mathrm{Mg}$ ha h $\mathrm{MJ}^{-1} \mathrm{~mm}^{-1} \mathrm{ha}^{-1}$.

Em relação à perda de solo nos tratamentos principais (Figura 4b), o alto valor observado no preparo convencional (PC) durante o ciclo cultural da soja, comparado aos valores dos demais tratamentos (reduzido - PR e semeadura direta -SD), é explicado pela mesma razão exposta antes, ou seja, maior concentração de erosividade das chuvas no período inicial de crescimento da cultura da soja, pelo fato de o solo estar com a sua superfície praticamente descoberta e bastante fragmentada, comparada às superfícies de solo nos demais tratamentos. Isso favoreceu a desagregação inicial do solo pela ação de impacto das gotas da chuva e seu posterior transporte pela ação da enxurrada. Exceto a particularidade de alta perda de solo no preparo convencional no início do ciclo cultural da soja, a perda de solo em geral foi baixa em todas as situações estudadas (considerando o valor de tolerância de perda de solo por erosão de

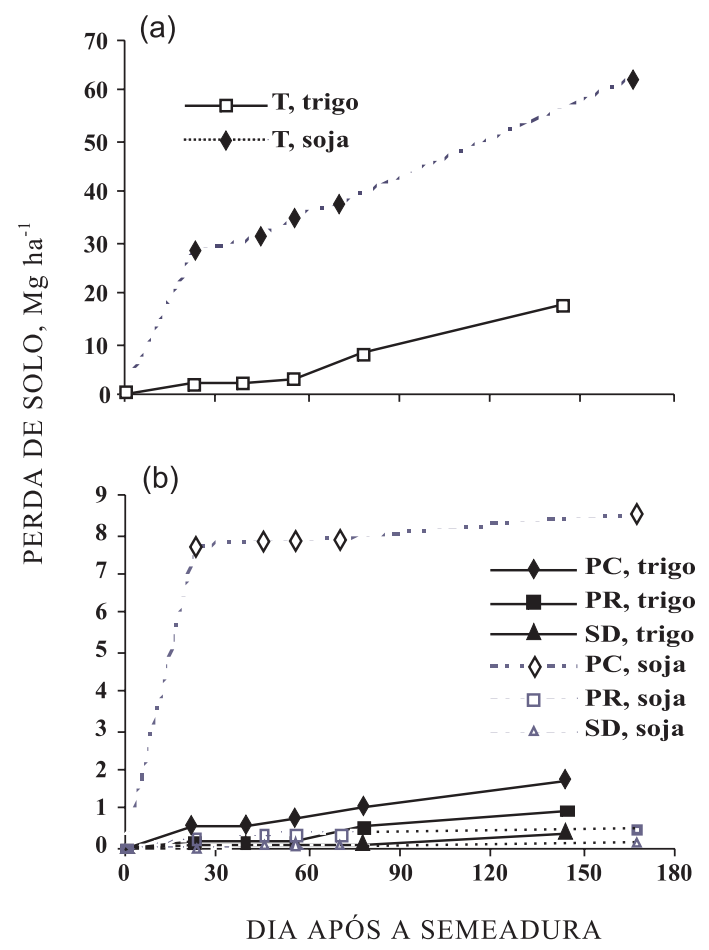

Figura 4. Perda de solo por erosão no tratamento sem cultivo (a) e nos tratamentos com cultivo (b), ao longo do desenvolvimento das culturas $(\mathrm{T}$ : testemunha; PC: preparo convencional; PR: preparo reduzido; SD: semeadura direta; obs.: em todos os casos, valores médios de três anos de experimentação).

5,0 Mg ha-1 para o solo do estudo, conforme reportado por Bertol \& Almeida, 2000). Isso pode ser explicado pelas condições físicas superficiais do solo favoráveis à resistência à erosão e à facilitação da infiltração de água nos preparos conservacionistas, como o preparo reduzido e a semeadura direta, usados neste trabalho, notadamente a cobertura por resíduo cultural e, ou, a rugosidade superficial induzida pelo preparo, independentemente do ciclo cultural das culturas, bem como pela menor erosividade das chuvas durante o ciclo cultural do trigo, independentemente do método de preparo do solo. Resultados semelhantes a esses também foram obtidos por Schick et al. (2000) e Guadagnin et al. (2005), na mesma região fisiográfica do estudo.

\section{Eficácia relativa de redução hídrica pluvial do solo}

Analisando primeiramente os dados de perda de água (Figura 5a), verifica-se que a eficácia relativa de redução do escoamento superficial dos tratamentos estudados foi maior no período de tempo correspondente ao ciclo cultural da soja do que do trigo. Isso é explicado pelo fato de o escoamento superficial ter sido menor no ciclo da primeira cultura, devido principalmente à 
maior diferença nos valores absolutos da variável em pauta entre os tratamentos principais $(\mathrm{PC}),(\mathrm{PR}) \mathrm{e}$ (SD) e o tratamento testemunha (T). Assim, no ciclo cultural do trigo, o preparo convencional reduziu a perda de água em $47 \%$, o preparo reduzido em $56 \%$ e a semeadura direta em $77 \%$, enquanto no ciclo cultural da soja a redução foi de, respectivamente, 62,75 e $90 \%$, comparados à perda absoluta máxima do tratamento testemunha (90 $\mathrm{mm}$ no ciclo cultural do trigo e $68 \mathrm{~mm}$ no ciclo cultural da soja). As razões para essas diferenças nos valores de eficácia relativa de redução do escoamento superficial entre tratamentos são as mesmas relacionadas na explicação das diferenças nos valores absolutos de perda de água, tratadas em item anterior.

Em relação à eficácia relativa de redução da perda de solo por erosão (Figura 5b), basicamente verificase o mesmo comportamento da redução da perda de água da chuva na forma de enxurrada, exceto a magnitude dos seus valores, tanto absolutos quanto relativos, com os maiores deles tendo ocorrido no ciclo cultural da soja e na mesma ordem de intensidade de preparo do solo. Assim, no ciclo cultural do trigo, o preparo convencional reduziu a perda de solo em $90 \%$, o preparo reduzido em $95 \%$ e a semeadura em $98 \%$, ao passo que no ciclo cultural da soja a redução foi de, respectivamente, 87, 99,2 e 99,7 \%. As razões para essas diferenças nos valores de eficácia relativa de perda de solo por erosão entre tratamentos são as mesmas relacionadas na explicação das diferenças nos valores absolutos de perda de solo, tratadas em item anterior.

Com base no que foi exposto, pôde-se verificar que o manejo do solo foi relativamente mais eficaz em reduzir a perda de solo por erosão do que a perda de água da chuva na forma de enxurrada, o que, de modo geral, é regra. Isso é explicado pelo fato de que todos os solos possuem um limite de capacidade de absorção e armazenamento de água. Ultrapassado esse limite, o excesso de água da chuva escoa sobre o terreno e as diferenças entre os sistemas de manejo do solo tendem a se igualar, o que já não acontece com a perda de solo. Esta poderá permanecer indefinidamente diferente, enquanto as condições físicas superficiais do solo garantirem a minimização do processo de desagregação do solo pela ação de impacto das gotas da chuva, independentemente da quantidade de escoamento superficial.

Para finalizar e chamar a atenção para a possível aplicação prática dos resultados obtidos, cabe dizer que, exceto o sistema de manejo com preparo convencional do solo, o qual, no somatório dos ciclos culturais (trigo e soja), apresentou perda média de solo de 10,2 Mg ha-1, os demais sistemas de manejo apresentaram perda de solo (1,5 e 0,5 $\mathrm{Mg} \mathrm{ha}^{-1}$, respectivamente para o sistema de manejo com preparo reduzido e para o com semeadura direta) dentro do limite tolerável (5,0 Mg ha-1, segundo Bertol \& Almeida, 2000, para o solo do estudo). Ressalta-se,
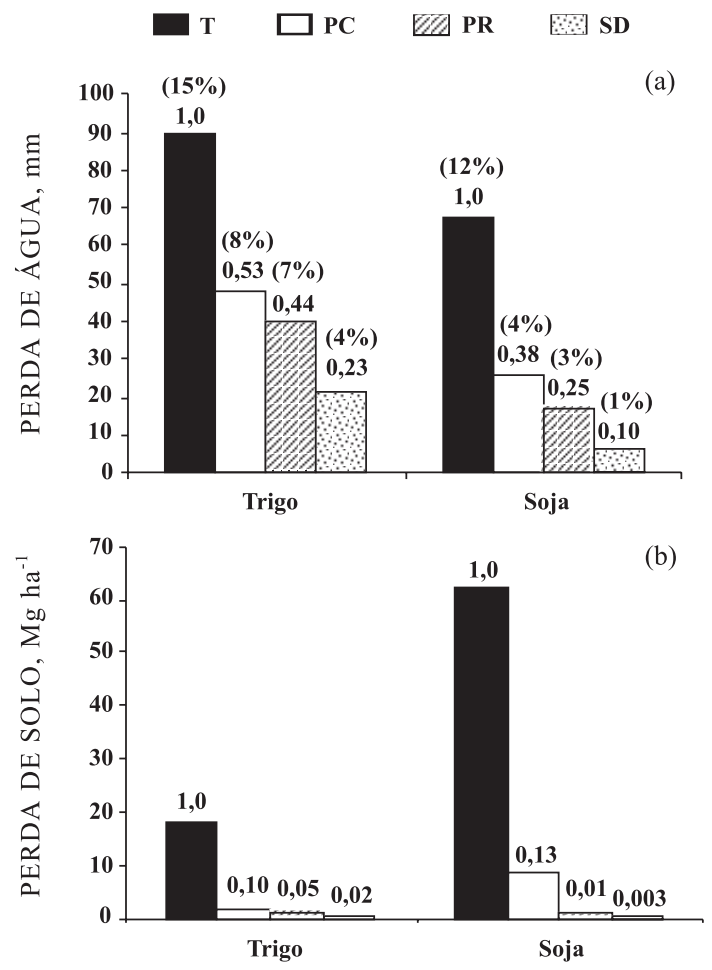

Figura 5. Perdas absolutas e relativas de água (a) e solo (b), nos tratamentos estudados (T: testemunha; PC: preparo convencional; PR: preparo reduzido; SD: semeadura direta; na figura a, valores sobre as colunas, entre parênteses, na forma percentual, correspondem à proporção de perda de água em relação ao total precipitado no ciclo da cultura, ao passo que valores sem parênteses, na forma decimal, correspondem à fração de perda de água em relação ao tratamento testemunha; em todos os casos, valores médios de três anos de experimentação.

entretanto, que essa tolerância visa, apenas, manter a capacidade produtiva do solo para o crescimento e desenvolvimento de plantas, sem qualquer significado no que se refere à poluição de água pelos sedimentos da erosão. Em adição, também é importante salientar que os valores referidos de perda de solo foram obtidos de um declive com $22 \mathrm{~m}$ de comprimento, o qual, comparado aos declives normalmente encontrados nas lavouras e levando em conta que a perda de solo por unidade de área varia com a potência 0,6 do comprimento de rampa (Wischmeier \& Smith, 1978), é extremamente curto, podendo, assim, tais valores facilmente ultrapassar os limites toleráveis de perda de solo por erosão, como chama a atenção Cogo et al. (2003). Independentemente disso, os valores de eficácia relativa de redução da perda de solo por erosão, obtidos neste trabalho $(0,23,0,06$ e 0,023 , respectivamente para os preparos de solo convencional, reduzido e semeadura direta), provisoriamente podem ser utilizados como substitutos do fator $\mathrm{C}$ - cobertura e 
manejo do solo do modelo EUPS (USLE) ou EUPSR (RUSLE) de predição da erosão, idealizados, respectivamente, por Wischmeier \& Smith (1978) e Renard et al. (1997), obedecidas a mesma sucessão cultural (trigo-soja) e as mesmas condições de clima de região fisiográfica (Planalto Sul-Catarinense). Por oportuno, os valores referidos de eficácia relativa de redução da erosão estão dentro da faixa normalmente reportada na literatura para o mesmo tipo de uso e manejo do solo, sendo, pois, confiáveis.

\section{CONCLUSÕES}

1. O período de maior potencial de erosão hídrica pluvial do solo na região do estudo correspondeu ao de meados da estação de primavera, quando normalmente são efetuadas as operações de preparo do solo e semeadura das culturas do período de primavera-verão.

2. A perda anual de água da chuva na forma de enxurrada, embora relativamente pequena em todas as situações estudadas (na pior delas - solo sem cultivo submetido ao preparo convencional - ela equivaleu, apenas, ao redor de $15 \%$ do total precipitado), foi maior no ciclo cultural do trigo do que no ciclo cultural da soja.

3. A perda anual de solo por erosão, igualmente como a perda de água, exceto as situações de solo sem cultivo submetido ao preparo convencional e solo cultivado com soja no mesmo método de preparo, cujos valores ficaram acima do limite tolerável, foi relativamente pequena em todas as situações estudadas.

4. A perda de solo por erosão foi proporcionalmente bem mais reduzida pelos sistemas de manejo estudados do que a perda de água da chuva na forma de enxurrada.

5. Os valores de eficácia relativa de redução da perda de solo por erosão determinados no estudo provisoriamente podem ser utilizados como substitutos do fator C - cobertura e manejo do solo do modelo EUPS ou EUPSR de predição da erosão, obedecidas as condições deste trabalho.

\section{LITERATURA CITADA}

ADAMS, J.E. \& ARKIN, G.F. A light interception method for measuring row crop ground cover. Soil Sci. Soc. Am. J., 41:789-792, 1977

ALLMARAS, R.R.; BURWELL, R.E. \& LARSON, W.E. Total porosity and roughness of the interrow zone as influenced by tillage. Washington, USDA, 1966. 22p. (Cons. Res. Report, 7)
ARMSTRONG, C.L. \& MITCHELL, J.K. Plant canopy characteristics and process wich effect transformation of rainfall properties. Trans. Am. Soc. Agron. Eng., 5:14001409, 1988 .

BEARE, M.H.; HENDRIX, P.F. \& COLEMAN, D.C. Waterstable aggregates and organic matter fractions in conventional and no tillage soils. Soil Sci. Soc. Am. J., 58:777-789, 1994.

BERTOL, I. Comprimento crítico de declive para preparos conservacionistas de solo. Porto Alegre, Universidade Federal do Rio Grande do Sul, 1995.185p. (Tese de Doutorado)

BERTOL, I. \& ALMEIDA, J.A. Tolerância de perda de solo por erosão para os principais solos do Estado de Santa Catarina. R. Bras. Ci. Solo, 24:657-668, 2000.

BERTOL, I.; SCHICK, J.; BATISTELA, O ; LEITE, D.; VISENTIN, D. \& COGO, N.P. Erosividade das chuvas e sua distribuição entre 1989 e 1998 no município de Lages(SC). R. Bras. Ci. Solo, 26:455-464, 2002.

BERTOL, I.; ALBUQUERQUE, J.A.; LEITE, D.; AMARAL, A.J. \& ZOLDAN JÚNIOR, W.A. Propriedades físicas do solo sob preparo convencional e semeadura direta em rotação e sucessão de culturas comparadas às do campo nativo. R. Bras. Ci. Solo, 28:155-163, 2004.

BERTOL, I.; AMARAL, A.J.; VIDAL VÁZQUEZ, E. GONZÁLEZ, A.P.; BARBOSA, F.T. \& BRIGNONI, L.F. Relações da rugosidade superficial do solo com o volume de chuva e com a estabilidade de agregados em água. $\mathrm{R}$. Bras. Ci. Solo, 30:543-553, 2006.

BURWELL, R.E.; ALLMARAS, R.R. \& SLONEKE, L.L. Structural alteration of soil surfaces by tillage and rainfall. J. Soil Water Conserv., 21:61-63, 1966.

BURWELL, R.E. \& LARSON, W.E. Infiltration as influenced by tillage induce random roughness and pore space. Soil Sci. Soc. Am. Proc., 33: 449-452, 1969.

CATANEO, A.; CASTRO FILHO, C. \& ACQUAROLE, R.M. Programa para cálculo de índices de erosividade das chuvas. R. Bras. Ci. Solo, 6:236-239, 1982.

CARVALHO, F.L.C.; COGO, N.P. \& LEVIEN, R. Eficácia de formas e doses de manejo de resíduo de culturas de trigo na redução da erosão hídrica do solo. R. Bras. Ci. Solo, 14:251-257, 1990.

CASTRO, L.G.; COGO, N.P. \& VOLK, L.B.S. Alterações na rugosidade superficial do solo pelo preparo e pela chuva em solo com cessamento de cultivo, na ausência e na presença de cobertura por resíduo cultural, e sua relação com a erosão hídrica. R. Bras. Ci. Solo, 30:339-352, 2006.

COGO, N.P. Uma contribuição à metodologia de estudo das perdas de erosão em condições de chuva natural. I. Sugestões gerais, medição dos volumes, amostragem e qualificação de solo e água da enxurrada (1 $1^{\mathrm{a}}$ aproximação). In: ENCONTRO NACIONAL DE PESQUISA SOBRE CONSERVAÇÃO DO SOLO, 2., Passo Fundo, 1978. Anais. Passo Fundo, Embrapa-CNPT, 1978. p.75- 98. 
COGO, N.P. Effect of residue cover, tillage induced roughness, and slope length on erosion and related parameters. West Lafayette, Purdue University, 1981. 346p. (Tese de Doutorado)

COGO, N.P.; MOLDENHAUER, W.C. \& FOSTER, G.R. Effect of residue cover, tillage-induced roughness, and runoff velocity on size distribution of eroded soil aggregates. Soil Sci. Soc. Am. J., 47:1005-1008, 1983.

COGO, N.P.; LEVIEN, R. \& SCHWARZ, R.A. Perdas de solo e água por erosão hídrica influenciadas por método de preparo, classes de declive e níveis de fertilidade do solo. R. Bras. Ci. Solo, 27:743-753, 2003.

DE MARIA, I. C. \& LOMBARDI NETO, F. Razão de perdas de solo e fator C para sistemas de manejo da cultura do milho. R. Bras. Ci. Solo, 21:263-270, 1997.

DISSMEYER, G.E. \& FOSTER, G.R. Estimating the cover management factor (C) in the universal soil loss equation for forest conditions. J. Soil Water Conserv., 36:235-240, 1981.

EMPRESA BRASILEIRA DE PESQUISA AGROPECUÁRIA EMBRAPA. Sistema Brasileiro de Classificação de Solos. Brasília, Serviço de Produção e Informação, Rio de Janeiro, Embrapa Solos, 1999. 412p.

DULEY, F.L. Surface factors affecting the rate of intake of water by soils. Soil Sci. Soc. Am. Proc., 4:60-64, 1939.

FOSTER, G.R.; McCOOL, D.K.; RENARD, K.E. \& MOLDENHAUER, W.C. Conversion of the universal soil loss equation to SI metric units. Soil Water Conserv., 36:355-359, 1981.

GHIDEY, F. \& ALBERTS, E.E. Runoff and soil losses as affected by corn and soybean tillage systems. J. Soil Water Conserv., 53:64-70, 1998.

GONZALEZ HIDALGO, J.C.; RAVENTOS, J. \& ECHEVARRIA, M.T. Comparison of sediment ratio curves for plants with different architetures. Catena, 29:333-340, 1996.
GUADAGNIN, J.C.; BERTOL, I.; CASSOL, P.C. \& AMARAL, A.J. Perdas de solo, água e nitrogênio por erosão hídrica em diferentes sistemas de manejo. R. Bras. Ci. Solo, 29:277-286, 2005.

HARTWIG, R.O \& LAFLEN, I.M. A meter stick method for measuring crop residue cover. J. Soil Water Conserv., 33:90-91, 1978.

HUDSON, N.W. Soil conservation. 3.ed. Ithaca, Cornell University Press, 1995. 324p.

JOHNSON, C.B. \& MOLDENHAUER, W.C. Effect of chisel versus moldboard plowing on soil erosion by water. Soil Sci. Soc. Am. J., 43:177-179, 1979.

LINDSTROM, W.J.; SCHUMACHER, T.E.; COGO, N.P. \& BLECHA, M.L. Tillage effects on water runoff and soil erosion after sod. J. Soil Water Conserv., 53:59-63, 1998.

KOHNKE, H. Soil physics. New York, McGraw-Hill, 1968. 224p.

RANEY, W.A. \& ZINGG, A.W. Principles of tillage. Yearbook of agriculture. Washington, 1957.p. 277-281.

RENARD, K.G.; FOSTER, G.A.; WEESIES, G.A. \& McCOLL, D.K. Preedicting soil erosion by water. A guide to conservation planning with the revised universal soil loss equation (RUSLE). Washington, USDA, 1997. (Agriculture Handbook, 703).

SCHICK, J.; BERTOL, I.; BALBINOT JUNIOR, A.A. \& BATISTELA, O. Erosão hídrica em Cambissolo Húmico alumínico submetido a diferentes sistemas de preparo e cultivo do solo: I. Perdas de solo e água. R. Bras. Ci. Solo, 24:427-436, 2000.

WISCHMEIER, W.H. \& SMITH D.D. Rainfall energy and its relationship to soil loss. Trans. Am. Geophys. Union, 39:285-291, 1958.

WISCHMEIER, W.H. \& SMITH D.D. Predicting rainfall erosion losses. Washington, USDA, Agricultural Research Service Handbook, 1978. 537p. 